\title{
Antimicrobial use over a four-year period using days of therapy measurement at a Canadian pediatric acute care hospital
}

\author{
Bruce R Dalton BScPhm PharmD ${ }^{1,2}$, Sandra J MacTavish MSc ${ }^{1,3}$, Lauren C Bresee BScPharm ACPR MSc PhD ${ }^{1,3,4}$, \\ Nipunie Rajapakse $M D^{5,6,7}$, Otto Vanderkooi $M D^{5,6,7}$, Joseph Vayalumkal MD $5,6,7$, John Conly MD $^{7,8,9,10}$
}

\begin{abstract}
BR Dalton, SJ MacTavish, LC Bresee, et al. Antimicrobial use over a four-year period using days of therapy measurement at a Canadian pediatric acute care hospital. Can J Infect Dis Med Microbiol 2015;26(5):253-258.
\end{abstract}

BACKGROUND: Antimicrobial resistance is a concern that is challenging the ability to treat common infections. Surveillance of antimicrobial use in pediatric acute care institutions is complicated because the common metric unit, the defined daily dose, is problematic for this population.

OBJECTIVE: During a four-year period in which no specific antimicrobial stewardship initiatives were conducted, pediatric antimicrobial use was quantified using days of therapy (DOT) per 100 patient days (PD) (DOT/100 PD) at the Alberta Children's Hospital (Calgary, Alberta) for benchmarking purposes.

METHODS: Drug use data for systemic antimicrobials administered on wards at the Alberta Children's Hospital were collected from electronic medication administration records. DOT were calculated and rates were determined using $100 \mathrm{PD}$ as the denominator. Changes over the surveillance period and subgroup proportions were represented graphically and assessed using linear regression.

RESULTS: Total antimicrobial use decreased from 93.6 DOT/100 PD to 75.7 DOT/100 PD (19.1\%) over the 2010/2011 through to the 2013/2014 fiscal years. During this period, a 20.0\% increase in PD and an essentially stable absolute count of DOT (2.9\% decrease) were observed. Overall, antimicrobial use was highest in the pediatric intensive care and oncology units.

DISCUSSION: The exact changes in prescribing patterns that led to the observed reduction in DOT/100 PD with associated increased PD are unclear, but may be a topic for future investigations.

CONCLUSION: Antimicrobial use data from a Canadian acute care pediatric hospital reported in DOT/100 PD were compiled for a four-year time period. These data may be useful for benchmarking purposes.

Key Words: Antimicrobial stewardship; Antimicrobial use; Days of therapy; Pediatric; Surveillance
L'utilisation d'antimicrobiens sur une période de quatre ans mesurée d'après les jours de traitement dans un hôpital pédiatrique canadien de soins aigus

HISTORIQUE : La résistance aux antimicrobiens nuit à la capacité de traiter les infections courantes. Il est difficile de surveiller l'utilisation d'antimicrobiens dans les établissements de soins aigus en pédiatrie, parce qu'il est difficile d'établir l'unité métrique habituelle, qui est la dose quotidienne définie, au sein de cette population.

OBJECTIF : Après quatre ans sans initiative de gérance des antimicrobiens précise, les chercheurs ont quantifié l'utilisation des antimicrobiens pédiatriques au moyen des jours de traitement (JdT) par 100 jours-patients (JP) (JdT/100 JP) à l'Alberta Children's Hospital de Calgary en vue d'une analyse comparative.

MÉTHODOLOGIE : À partir des dossiers électroniques sur l'administration des médicaments, les chercheurs ont colligé les données sur l'utilisation des antimicrobiens systémiques administrés dans les services de l'Alberta Children's Hospital. Ils ont calculé les JdT et déterminé les taux à l'aide du dénominateur 100 JP. Ils ont représenté graphiquement les changements pendant la période de surveillance et les proportions des sous-groupes et les ont évalués à l'aide de la régression linéaire. RÉSULTATS : L'utilisation totale d'antimicrobiens a reculé de 93,6 JdT/100 JP à 75,7 JdT/100 JP (19,1 \%) entre les exercices 2010-2011 et 2013-2014. Pendant cette période, les chercheurs ont observé une augmentation de 20,0 \% des JP et une numération absolue de JdT pratiquement stable (diminution de 2,9\%). Dans l'ensemble, l'utilisation d'antimicrobiens était plus élevée dans les unités pédiatriques de soins intensifs et d'oncologie.

EXPOSÉ : On ne sait pas exactement quels changements aux profils de prescription ont donné lieu à la réduction observée de JdT/100 JP et à l'augmentation connexe de JP, mais cette question pourrait faire l'objet de prochaines recherches.

CONCLUSION : Pendant quatre ans, les chercheurs ont compilé les données sur l'utilisation d'antimicrobiens en JdT/100 JP dans un hôpital pédiatrique canadien de soins aigus. Ces données peuvent être utiles dans une analyse comparative.

older ineffective agents has made antimicrobial resistance an urgent situation (2). To assess antimicrobial stewardship initiatives, baseline measurement of antimicrobial use is required. Defined daily doses are commonly used to assess antimicrobial use in adult medicine but is based on adult dosing and, therefore, is problematic for assessment in pediatric to result in increased mortality, morbidity and reduced quality of life $(1,2)$. The lack of development of new antimicrobials to replace the

${ }^{1}$ Department of Pharmacy Services, Alberta Health Services, Calgary; ${ }^{2}$ O'Brien Institute of Public Health, Cumming School of Medicine,

University of Calgary, Calgary, Alberta; ${ }^{3}$ School of Pharmacy, University of Waterloo, Waterloo, Ontario; ${ }^{4}$ Department of Community Health

Sciences, Cumming School of Medicine; ${ }^{5}$ Department of Pediatrics, Section of Infectious Diseases; ${ }^{6}$ Department of Medicine, Cumming School

of Medicine, University of Calgary; 7 Alberta Children's Hospital Research Institute, Alberta Health Services; ${ }^{8}$ Department of Pathology and

Laboratory Medicine, Cumming School of Medicine; ${ }^{9}$ Synder Institute for Chronic Diseases; ${ }^{10}$ Department of Microbiology, Immunology and

Infectious Diseases, Cumming School of Medicine, University of Calgary, Calgary, Alberta

Correspondence: Dr Bruce R Dalton, Department of Pharmacy Services, Foothills Medical Centre, 1403-29th Street Northwest, Calgary,

Alberta T2N 2T9. Telephone 403-944-8317, fax 403-944-1355, e-mail bruce.dalton@albertahealthservices.ca 
populations (5). The WHO International Working Group for Drug Statistics Methodology do not recommend that defined daily doses be used in assessment of antimicrobial use in pediatrics $(6,7)$. In children, the days of therapy (DOT) measurement is preferred for measuring antibiotic use because it is independent of age- and weight-related differences in doses (6). The DOT unit of measure is defined as one day in which a patient is given a drug, regardless of dose (6). The ability to quantify pediatric antimicrobial use through DOT measurements provides a value that is numerically comparable with adult antibiotic use, more applicable to a variety of populations and is less likely to be affected by different dosing schemes $(6,8)$.

The objectives of the present study were to initiate antimicrobial surveillance at the Alberta Children's Hospital (ACH; Calgary, Alberta) over a four-year period, to quantify pediatric antimicrobial use and to provide a basic descriptive epidemiological analysis of our data. There are few published data available regarding Canadian antimicrobial use in pediatric acute care settings. The present study provides an overview of systemic antibacterial (J01) and antifungal (J02) use according to ward at the $\mathrm{ACH}$, covering fiscal years (April through March) from April 2010 to March 2014.

\section{Setting}

\section{METHODS}

The ACH is an acute care tertiary pediatric centre located in Calgary, Alberta. A new structure opened in 2007 that included units for oncology/hematology/bone marrow transplants, pediatric intensive care, neonatal intensive care, day surgery and mental health, as well as three general medicine/surgery units. The present investigation quantified antimicrobial use over a 51-month period from January 2010 to March 2014. During the study period, the total number of inpatient beds available were 125 in January 2010 and 141 in March 2014. Wards increasing their capacity included general medicine/surgery (increased by two beds), neonatal intensive care (increased by six beds) and pediatric intensive care (increased by eight beds). Sunrise Clinical Manager version 5.8 (Eclipsys Corporation, USA) was introduced for use in 2009, featuring electronic prescribing, patient care management, laboratory and diagnostic imaging results, and electronic medication administration records (eMAR), for all patients admitted to the $\mathrm{ACH}$. Tools for antimicrobial stewardship, such as pediatric antimicrobial reference cards, were provided to prescribers and other health care professionals, but no specific interventional initiatives had been conducted in recent years. There were no notable formulary changes in high-use agents during the study period.

\section{Data collection}

Drug use data for all provincial inpatient formulary systemic antibacterial and systemic antifungal medications administered on wards at the ACH were collected from the Sunrise Clinical Manager eMAR system, which was used by nursing staff to record the details of administration of each dose of medication. Patient days (PD) data were collected from the Data Integration Measurement and Reporting unit of Alberta Health Services, who collects and provides health care statistics for Alberta Health Services facilities. Preoperative antimicrobial prophylaxis given in the operating room may not be captured electronically and, therefore, was excluded from analysis. Antibiotics given in the emergency department and ambulatory clinics were also excluded from the present study.

\section{Drug classification}

Drugs were classified based on the WHO anatomical therapeutic chemical classifications, and systemic antibacterial and antifungal agents were included and reported as the sum of those two groups and separately. Agents were grouped into clinically relevant drug categories, derived by consensus of the Calgary Zone Antimicrobial Stewardship Committee (CASC) as follows: broad-spectrum Gram-negative active agents (BGNA) that included piperacillin/tazobactam, carbapenems and ticarcillin/clavulanate; Gram-positive antimicrobial-resistant organism active agents that included vancomycin, linezolid, tigecycline and daptomycin; narrow-spectrum agents that included first-generation cephalosporins, ampicillin, amoxicillin, penicillin $\mathrm{G}$, penicillin $\mathrm{V}$, cloxacillin and aminoglycosides; and second- to fifth-generation cephalosporins. Agents not included in any of the above categories were included as 'unclassified' antibacterial agents.

\section{Units of measure}

Antimicrobial use was measured in DOT for antimicrobials signed off on eMAR, consistent with methods previously described $(5,6,8)$. If a single patient received two different antimicrobial agents within one day, it counted as two DOT (5). The rate of antimicrobial use was expressed as DOT/100 PD, consistent with Canadian recommendations for expressing antimicrobial use (9). DOT were assigned to a ward based on the location of the patient at the time of the first administration of the antimicrobial during each $24 \mathrm{~h}$ period. Centrality and dispersion of reported means and standard deviations for site-level use were determined using Microsoft Excel 2010 (Microsoft Corporation, USA). Percentage changes were expressed in terms of use rate relative to the baseline (2011 fiscal year) for all agents and wards. Hospital-level use was analyzed in terms of measures for total antimicrobials (DOT and DOT/100 PD) and the hospital capacity measure PD against time (fiscal period) using ordinary least squares regression for the period of April 2010 to March 2014 and reported Pearson correlation. $\mathrm{P}<0.05$ was considered to be statistically significant. Three months of data were excluded to capture seasonal variations equitably. SPSS version 19 (IBM Corporation, USA) was used for calculation of correlation coefficients. Proportion of each drug class measured was expressed as percentage of total.

\section{Ethical considerations}

The A pRoject Ethics Community Consensus Initiative (ARECCI) ethics screening tool (10) was completed to assess the ethical risk to study participants and whether a review through a research ethics board was necessary. The assessment tool included consideration of the positions of the individuals processing the data (in the present case, a staff member and a summer student). The present project was deemed to be a quality improvement project with 'minimal risk' to participants and, as a result, ethics approval was deemed to be unnecessary. The ARECCI ethics guidelines for quality improvement and evaluation projects were used to guide the present project.

\section{RESULTS}

Data from ACH eMARs showed a steady decrease in antimicrobial use at the ACH over the 2011 to 2014 fiscal years (Figure 1A.) Total antimicrobial use decreased from 93.6 DOT/100 PD to 75.7 DOT/100 PD (19.1\% decrease over the four years [Table 1]). This decrease was reciprocally associated with a change in PDs (increase by $20.0 \%$, Figure 1B.), but change in absolute number of DOT was minor $(-2.9 \%)$ (Figure 1C). In terms of administration, the majority of antimicrobials were given parenterally $(73.6 \%$ to $75.3 \%)$. Oral antimicrobial use accounted for $23.1 \%$ to $25.0 \%$ of total antimicrobial use each year and inhaled antimicrobials represented $<1 \%$ of DOT for all years.

The percent change in individual antimicrobial use at the $\mathrm{ACH}$ over the four-year period was determined and reported along with antimicrobial use for each fiscal year (Table 1). A decline in the use of most individual agents was observed during the study period, with a few notable exceptions. These exceptions included oral amoxicillin/ clavulanate (35.5\% increase), amoxicillin (29.8\% increase), parenteral ceftriaxone $(66.9 \%$ increase), as well as several other agents of which use did not exceed 1 DOT/100 PD (Table 1). Agents from each of the CASC-derived categories decreased in use from 2011 to 2014 and were numerically dominated by one or two agents. Specifically, the BGNA group decreased by $24.1 \%$ and piperacillin/tazobactam accounted for $68.6 \%$ of the use. Vancomycin was dominant in the Gram-positive antimicrobial-resistant active agents group, accounting for $95.1 \%$ of the group, and the use of this group decreased by $35.7 \%$. 
The use of narrow-spectrum agents decreased by $16.4 \%$ and ampicillin and cefazolin made up $55.0 \%$ of the category. Cefotaxime and ceftriaxone accounted for $77.9 \%$ of the second- to fifth-generation cephalosprins group, which declined by $26.8 \%$ over four years. Fluconazole was the antifungal with the highest mean use of 4.17 DOT/100 PD, accounting for $74.9 \%$ of antifungal use (Table 1). The decrease in use of systemic antibacterials unclassified in the system was $18.2 \%$ and systemic antifungal agents fell from 5.9 DOT/100 PD to 4.8 DOT/100 PD from 2011 to 2013, but increased again in 2014 to 6.0 DOT/100 PD (Table 1 ).

Individual ward use summaries for 2014, 2011 to 2014 change and proportion of each CASC-derived drug category are presented in Table 2. Different patterns of both types and amounts of anti-infectives used on various wards were observed. The pediatric intensive care unit had the highest antimicrobial mean ( \pm SD) use of $129.9 \pm 6.1$ DOT/100 PD, of which narrow-spectrum agents were the largest portion. In addition, relative to medical/surgical units, there was a higher portion of BGNA $(17.3 \%$ versus $4.2 \%$ to $6.1 \%)$ and Gram-positive antimicrobial-resistant active agents ( $16.1 \%$ versus $3.6 \%$ to $8.8 \%$ ) use on the pediatric intensive care unit. The oncology ward also experienced a very high use of total antibacterial and antifungal drugs (mean $120.7 \pm 13.5$ DOT/100 PD), which decreased by $17.4 \%$ over the four years of surveillance and was notable for high use of antifungal agents $(27.9 \%)$.

\section{DISCUSSION}

A $19.1 \%$ decrease in the rate of DOT/100 PD over a four-year period was observed. Awareness of the directions of trends is valuable for those initiating new antimicrobial stewardship initiatives because evaluations of these programs should consider trends that are already occurring. We observed an associated increase in PDs by $20 \%$ with little change in absolute DOT count (Figures 1B and 1C, Table 2). However, the knowledge that the denominator of the rate of antimicrobial use changed while the numerator was static does not provide extensive insight into prescribing patterns, the quality of antimicrobial use or the infectious acuity of the patients. Investigations to determine whether changes in the number of admissions receiving antimicrobials or whether the length of therapy on antimicrobials occurred are potential areas of further inquiry.

Internally, in our institution, a categorization scheme of antimicrobial agents that groups agents that may have common therapeutic use together (eg, broad-spectrum Gram-negative activity) was developed because traditional classification schemes heavily rely on the chemical structure, which may have less relevance for antimicrobial use surveillance. It is recognized that there are agents that are used to a significant degree that have not been added into a category; however, it was believed that these would be better left unclassified, as opposed to being included in a category that would, therefore, become less specific. For example, had amoxicillin/clavulanate been added to the BGNA group, this would broaden the therapeutic indications that the group covers. In all four CASC-derived antibacterial drug categories, there was a decrease in rate of antimicrobial use by $16.5 \%$ to $35.7 \%$ from the 2011 to 2014 fiscal years (Table 1). Among individual agents, there were a few increases in rate of use, such as with ceftriaxone, (2.68 DOT/100 PD to 4.48 DOT/100 PD, 66.9\%) (Table 1). We are unclear on the reasons for these observed rate increases; however, in the case of ceftriaxone, most of the increase in use rate occurred during the 2010/2011 fiscal year (2.68 DOT/100 PD to 4.12 DOT/100 PD; $51.8 \%)$. The change observed may reflect a shift from the use of cefotaxime to ceftriaxone because both are third-generation cephalosporins with similar spectrum of activity. Over the period of observation, the total rate of the two agents decreased by $15.4 \%$ (11.00 DOT/100 PD to 9.26 DOT/100 PD).

The data revealed that the highest antibacterial and antifungal use took place in the pediatric intensive care unit, where the fouryear mean value was 129.9 DOT/100 PD. The hematology-oncology

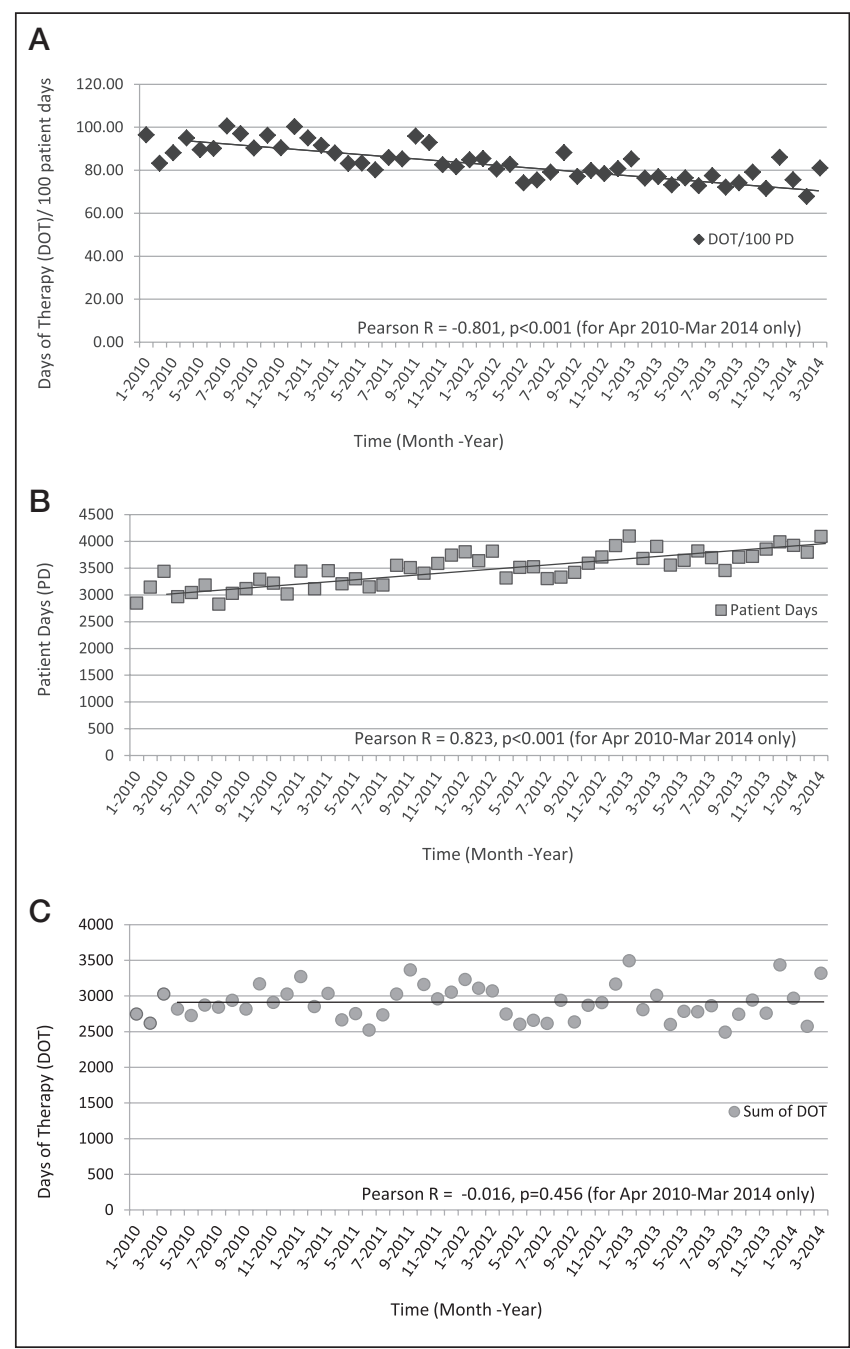

Figure 1) Alberta Children's Hospital (ACH, Calgary, Alberta) systemic antibacterial and antifungal use according to year and month, mean ( \pm SD) $(83.49 \pm 8.14$ days of therapy [DOT]/100 patient days [PD]) (A); ACH PD (denominator of the data in Figure 1A), mean $3502.27 \pm 315.92 \mathrm{PD}(\mathrm{B}) ; \mathrm{ACH}$ systemic antibacterial and antifungal use according to year and month (numerator of the data in Figure 1A), mean 2908.33 \pm 240.49 DOT (C); Period from from January 2010 to April 2014; Regression line and descriptive statistics calculated from April 2010 to March 2014 (see text for explanation)

ward had lower overall use than the pediatric intensive care unit and a greater use of antifungals. This high use of anti-infectives is not surprising because bacterial and fungal infections are common in these two patient populations $(11,12)$.

It is difficult to compare antimicrobial use at one institution with another because of differences in patient populations and because there are limited published data. Five relevant recent studies using DOT to quantify antimicrobial use in pediatric acute care centres (13-16) or the pediatric patient population in acute care general hospitals (6) were identified. Study population, specific antimicrobials reported and changes over time of the reports are detailed in Table 3, along with results of our surveillance (on systemic antimicrobials) for comparison. Cited references reported DOT/1000 PD; therefore, we converted their results to DOT/100 PD to ease comparison. Others have noted reductions in overall antimicrobial use assessed by DOT/100 PD (15), but have not reported on the change in either absolute count of DOT or PDs, which may be useful dimensions for assessment of the success of antimicrobial stewardship initiatives. 
TABLE 1

Antimicrobial use according to days of therapy per 100 patient days and fiscal year (month of year end)

\begin{tabular}{|c|c|c|c|c|c|c|c|}
\hline & \multirow{2}{*}{$\begin{array}{l}\text { Anatomical } \\
\text { therapeutic } \\
\text { chemical code }\end{array}$} & \multicolumn{4}{|c|}{ Year } & \multirow{2}{*}{$\begin{array}{c}2011-2014 \\
\text { change in } \\
\text { use, } \%\end{array}$} & \multirow{2}{*}{$\begin{array}{c}\text { Proportion } \\
\text { of agent in } \\
\text { group (all } \\
\text { years), } \% \\
\end{array}$} \\
\hline & & 2011 & 2012 & 2013 & 2014 & & \\
\hline Broad-spectrum Gram-negative agents* & & 9.97 & 8.70 & 8.35 & 7.57 & -24.1 & - \\
\hline Ertapenem & J01DH03 & 0.14 & 0.17 & 0.24 & 0.11 & -16.7 & 1.9 \\
\hline Meropenem & J01DH02 & 3.41 & 2.38 & 2.64 & 1.76 & -48.5 & 29.5 \\
\hline Gram-positive antimicrobial-resistant organism active agents* & & 8.69 & 7.96 & 6.82 & 5.59 & -35.7 & - \\
\hline Linezolid & J01XX08 & 0.21 & 0.25 & 0.67 & 0.25 & 17.7 & 4.8 \\
\hline \multirow[t]{2}{*}{ Vancomycin } & A07AA09 (O) & 8.48 & 7.71 & 6.10 & 5.34 & -37.0 & 95.1 \\
\hline & J01XA01 (P) & & & & & & \\
\hline Narrow-spectrum agents" & & 29.37 & 26.17 & 25.57 & 24.54 & -16.4 & - \\
\hline Amoxicillin & J01CA04 & 2.00 & 1.67 & 2.48 & 2.60 & 29.8 & 8.3 \\
\hline Gentamicin & J01GB03 & 5.74 & 5.05 & 3.81 & 3.56 & -38.0 & 17.2 \\
\hline Penicillin G sodium & J01CE01 & 0.71 & 0.66 & 0.59 & 0.37 & -48.3 & 2.2 \\
\hline Penicillin $\vee$ potassium & J01CE02 & 0.51 & 0.30 & 0.60 & 0.32 & -37.0 & 1.6 \\
\hline Tobramycin & J01GB01 & 2.58 & 1.96 & 2.04 & 1.56 & -39.5 & 7.7 \\
\hline Second- to fifth-generation cephalosporins" & & 16.04 & 14.06 & 12.74 & 11.73 & -26.8 & - \\
\hline Cefepime & J01DE01 & 0.02 & 0.02 & 0.10 & 0.67 & 3519.0 & 1.5 \\
\hline Cefixime & J01DD08 & 0.28 & 0.32 & 0.18 & 0.21 & -23.7 & 1.8 \\
\hline Cefotaxime & J01DD01 & 9.32 & 6.78 & 6.33 & 4.78 & -48.8 & 49.9 \\
\hline Cefprozil & J01DC10 & 0.91 & 0.70 & 0.28 & 0.19 & -79.7 & 3.8 \\
\hline Ceftazidime & J01DD02 & 1.54 & 1.28 & 1.15 & 1.16 & -24.8 & 9.4 \\
\hline Ceftriaxone & J01DD04 & 2.68 & 4.12 & 4.01 & 4.48 & 66.9 & 28.0 \\
\hline Erythromycin & J01FA01 & 0.62 & 0.20 & 0.06 & 0.23 & -63.4 & 1.4 \\
\hline Levofloxacin & J01MA12 & 0.68 & 0.46 & 0.48 & 0.61 & -10.5 & 2.8 \\
\hline Metronidazole & J01XD01 & 7.90 & 8.53 & 7.63 & 7.12 & -10.0 & 39.1 \\
\hline Nitrofurantoin & J01XE01 & 0.50 & 0.45 & 0.42 & 0.34 & -31.9 & 2.1 \\
\hline Piperacillin & J01CA12 & 0.05 & 0.00 & 0.01 & 0.00 & -100.0 & 0.1 \\
\hline Sulfamethoxazole/trimethoprim & J01EE01 & 4.18 & 3.89 & 3.78 & 3.47 & -17.0 & 19.2 \\
\hline Tetracycline & J01AA07 & 0.05 & 0.00 & 0.04 & 0.00 & -100.0 & 0.1 \\
\hline Trimethoprim & J01EA01 & 0.30 & 0.32 & 0.46 & 0.15 & -49.4 & 1.5 \\
\hline Systemic antifungals & & 5.95 & 5.38 & 4.80 & 6.02 & 1.3 & - \\
\hline Amphotericin B & J02AA01 & 0.03 & 0.00 & 0.05 & 0.08 & 143.6 & 0.8 \\
\hline Amphotericin B liposomal & J02AA01-lipid & 0.23 & 0.15 & 0.69 & 0.24 & 2.5 & 5.9 \\
\hline Caspofungin & J02AX04 & 0.16 & 0.00 & 0.01 & 0.00 & -100.0 & 0.8 \\
\hline Fluconazole & J02AC01 & 4.99 & 4.39 & 3.06 & 4.17 & -16.5 & 74.9 \\
\hline Itraconazole & $\mathrm{J} 02 \mathrm{ACO} 2$ & 0.03 & 0.00 & 0.00 & 0.24 & 592.3 & 1.2 \\
\hline Micafungin & J02AX05 & 0.03 & 0.22 & 0.61 & 0.46 & 1330.6 & 6.0 \\
\hline Posaconazole & J02AC04 & 0.00 & 0.01 & 0.00 & 0.00 & NA & 0.1 \\
\hline Voriconazole & $\mathrm{J} 02 \mathrm{AC} 03$ & 0.47 & 0.61 & 0.39 & 0.84 & 79.5 & 10.4 \\
\hline
\end{tabular}

*No daptomycin, fifth-generation cephalosporin, imipenem/cilastatin, ticarcillin/clavulanate, penicillin $\mathrm{G}$ benzathine or posaconazole use occurred during the study period; Cefoxitin had 0.1 days of therapy per 100 patient days in 2012; Tigecycline and amikacin each had 0.1 days of therapy per 100 patient days in 2013; Streptomycin had 0.1 days of therapy per 100 patient days in 2014. J01 Systemic antimicrobial agents-WHO anatomical therapeutic chemical classification; J02 Systemic antifungal agents-WHO anatomical therapeutic chemical classification. Refer to methods section for further explanation. NA Not available; O Oral, P parenteral 
TABLE 2

Antimicrobial use according to ward type

\begin{tabular}{|c|c|c|c|c|c|c|c|c|}
\hline \multirow[b]{3}{*}{ Ward } & \multirow{2}{*}{\multicolumn{2}{|c|}{2014 total DOT/100 PD change in use }} & \multicolumn{6}{|c|}{ Proportion of ward or hospital total in fiscal year 2014, \% } \\
\hline & & & & & & & & \\
\hline & (all J01 \& J02 agents) & $(\%)$ & BGNA & GPAA & NSA & SFGC & Other J01 & $\mathrm{J} 02$ \\
\hline Whole hospital & 71.1 & -20.2 & 10.4 & 7.3 & 32.1 & 14.6 & 27.2 & 8.5 \\
\hline Medical/surgical units 1-3 & 70.0 & -21.8 & 5.0 & 6.3 & 38.6 & 17.1 & 30.2 & 2.7 \\
\hline $\begin{array}{l}\text { Oncology/bone marrow } \\
\text { transplant }\end{array}$ & 112.2 & -17.4 & 22.5 & 4.0 & 10.2 & 6.3 & 26.6 & 30.5 \\
\hline Pediatric intensive care unit & 129.8 & -5.4 & 17.3 & 16.1 & 24.0 & 19.4 & 19.4 & 3.9 \\
\hline Neonatal intensive care unit & 62.1 & $-11.2^{*}$ & 13.3 & 13.3 & 43.1 & 12.5 & 12.7 & 5.0 \\
\hline Mental health & 3.1 & 32.2 & 0.0 & 0.0 & 13.3 & 0.0 & 86.7 & 0.0 \\
\hline Day surgery & 60.4 & 11.3 & 0.8 & 0.3 & 73.4 & 2.0 & 23.5 & 0.0 \\
\hline
\end{tabular}

${ }^{*}$ Neonatal intensive care unit change in rate from 2012 (first complete fiscal year) to 2014; Year designation refers to fiscal year (April-March) year-end month. BGNA Broad-spectrum Gram-negative active agents; DOT/100 PD Days of therapy per 100 patient days; ICU Intensive care unit; J01 Systemic antimicrobial agents-WHO anatomical therapeutic chemical classification; J02 Systemic antifungal agents-WHO anatomical therapeutic chemical classification; GPAA Grampositive antimicrobial-resistant organism active agents; NSA Narrow-spectrum agents; SFGC Second-to fifth-generation cephalosporins. Refer to methods section for further explanation

TABLE 3

Other studies reporting inpatient pediatric antimicrobial use

\begin{tabular}{|c|c|c|c|c|c|}
\hline Reference & $\begin{array}{l}\text { Years of } \\
\text { surveillance }\end{array}$ & Patient population & $\begin{array}{l}\text { Antibiotics } \\
\text { reported }\end{array}$ & $\begin{array}{l}\text { Range reported } \\
\text { (DOT/100 PD)* }\end{array}$ & Change over years \\
\hline 6 & 2002-2007 & $\begin{array}{l}\text { Pediatric population in general acute care centres } \\
\text { in the United States }\end{array}$ & $\mathrm{J} 01$ & $53.7-56.0$ & None \\
\hline 13 & 2007-2010 & $\begin{array}{l}\text { One acute pediatric centre in the United States located } \\
\text { within a larger adult hospital }\end{array}$ & $\begin{array}{l}\mathrm{J} 01, \mathrm{~J} 02 \\
\text { and J05 }\end{array}$ & $72.9-81.5$ & $\begin{array}{l}\text { Increase in broad-spectrum agents; } \\
\text { decrease in narrow-spectrum } \\
\text { agents }\end{array}$ \\
\hline 14 & 2010 & Specific high-use disease groups including cystic fibrosis, & $\mathrm{J} 01$ & 69.8 & NA \\
\hline
\end{tabular}

other patients with pneumonia, skin and soft tissue infec-

tions, or an appendectomy in a network of freestanding

children's hospitals in the United States

$\begin{array}{lllll}\text { 15,16 } & 2004-2014 & \begin{array}{l}\text { Network of freestanding children's hospitals in the United } \\ \text { States }\end{array} & \text { J01 } & \text { Decrease } \\ \text { Present } & 2011-2014 & \text { One freestanding pediatric hospital in Canada } & \text { J01 } & 67.1-85.7\end{array}$

*Range reported: antimicrobial total use from each reference was converted into days of therapy per 100 patient days (DOT/100 PD) to compare with the Alberta Children's Hospital data. J01 Systemic antibacterial agents-WHO anatomical therapeutic chemical classification; J02 Systemic antifungal agents-WHO anatomical therapeutic chemical classification; J05 Systemic antiviral agents-WHO anatomical therapeutic chemical classification; NA Not available

The present report established a baseline of antimicrobial use at the $\mathrm{ACH}$ for future reference and may be useful to other pediatric institutions in Canada. We acknowledge that the present study has limitations. We did not evaluate the use of agents in terms of appropriateness of the therapy or their use as treatment versus prophylaxis. Antimicrobial use intensity may drive the development of resistance, regardless of the appropriateness of the therapy for an individual patient and, therefore, is an accepted metric for antimicrobial resistance surveillance purposes $(17,18)$. Some data were excluded because the location at the time of administration of the antimicrobial was missing; however, these were few and unlikely to significantly alter our results. Perioperative doses are commonly given in the operating theatre, where it is uncommon practice to record their administration on the eMAR. Depending on the procedure, surgical patients may also receive doses of the same prophylactic agent postoperatively outside of the operating theatre on the same day and a DOT would be assigned to the patients; therefore, we believe this limitation to be minor. There is occasional nonformulary antimicrobial use at $\mathrm{ACH}$ that was not captured in the eMAR data, but the provincial inpatient formulary is mostly inclusive of systemic antibacterials and systemic antifungals because of the diverse populations the formulary serves. The possibility exists that some doses signed off by nurses were subsequently not administered to the patient, but equally, there is the possibility of doses having been given but not signed off. We do not have data to assess these possibilities at this time but believe that if such events occur they are infrequent and would not change our findings to a clinically relevant degree. We believe that the eMAR is a better source of data than pharmacy dispensing systems, and have previously observed a $20 \%$ greater antimicrobial drug use with pharmacy dispensing system data versus eMAR data using the same metric units (19). In addition, a simple linear regression of the monthly data points of total antimicrobial use without adjustment for seasonality was performed. So that one season was not over-represented, we only used the latter entire four-year period of the total 51 months of observation in calculation of regression coefficient and summary statistics and excluded data for three months. Without a seasonal variable fitted to our model, prediction of use in a specific future month(s) may not be accurate; however, we do not intend that this model be used for that purpose. Despite these limitations, the strengths of the present report include the use of DOT as a primary metric, which is more appropriate for pediatric patients than the WHO-recommended anatomical therapeutic chemical per defined daily dose system, which uses a standardized adult dose that is not applicable given the weight-based dosing regimens used in children.

In conclusion, we believe surveillance of antimicrobial use is an integral part of antimicrobial stewardship. In the pediatric acute care setting, there have been only a few published surveillance projects 
using utilization metrics appropriate for this population but the need for such information in this unique patient population is as important as in the adult population. Our results contribute to this literature and demonstrate the importance of ongoing antimicrobial use surveillance in a pediatric population.

\section{REFERENCES}

1. World Health Organization. Antimicrobial resistance fact sheet $\mathrm{N}^{\circ} 194$. <www.who.int/mediacentre/factsheets/fs194/en/> (Accessed June 3, 2014).

2. World Health Organization. Antimicrobial resistance global report on surveillance. $<$ http://apps.who.int/iris/ bitstream/10665/112642/1/9789241564748_eng.pdf?ua=1> (Accessed June 25, 2014).

3. Centers for Disease Control and Prevention. Antibiotic resistance threats in the United States, 2013. <www.cdc.gov/drugresistance/ threat-report-2013/pdf/ar-threats-2013-508.pdf > (Accessed December 15, 2014).

4. Public Health Agency of Canada. Antimicrobial resistance and use in Canada: A federal framework for action. <http:// healthycanadians.gc.ca/alt/pdf/drugs-products-medicamentsproduits/antibiotic-resistance-antibiotique/antimicrobial-frameworkcadre-antimicrobiens-eng.pdf> (Accessed December 15, 2014).

5. Polk RE, Fox C, Mahoney A, Letcavage J, MacDougall C. Measurement of adult antibacterial drug use in 130 US hospitals: Comparison of defined daily dose and days of therapy. Clin Infect Dis 2007;44:664-70.

6. Pakyz AL, Gurgle HE, Ibrahim OM, Oinonen MJ, Polk RE. Trends in antibacterial use in hospitalized pediatric patients in United States academic health centers. Infect Control Hosp Epidemiol 2009;30:600-3.

7. WHO Collaborating Centre for Drug Statistics Methodology. Guidelines for ATC classification and DDD assignment 2014. <www.whocc.no/filearchive/publications/2014_guidelines.pdf> (Accessed June 25, 2014).

8. Kubin CJ, Jia H, Alba LR, Yoko Furuya E. Lack of significant variability among different methods for calculating antimicrobial days of therapy. Infect Control Hosp Epidemiol 2012;33:421-3.

9. Hutchinson JM, Patrick DM, Marra F, et al. Measurement of antibiotic consumption: A practical guide to the use of the anatomical therapeutic chemical classification and defined daily dose system methodology in Canada. Can J Infect Dis Med Microbiol 2004;15:29-35.
ACKNOWLEDGEMENTS: The authors gratefully acknowledge the contribution of Kevin Lonergan, who extracted data from the Sunrise Clinical Manager eMAR system for analysis.
10. Alberta Innovates Health Solutions. ARECCI Tool. $<$ www.aihealthsolutions.ca/arecci/screening/55035/ af524cd22bdf1743ecbd0fdd5f43766f> (Accessed December 4, 2014).

11. Arnold C. Decreasing antibiotic overuse in neonatal intensive care units: Quality improvement research. Proc (Bayl Univ Med Cent) 2005; 18:280-4.

12. Cecinati V, Principi N, Brescia L, Esposito S. Antibiotic prophylaxis in children with cancer or who have undergone hematopoietic cell transplantation. Eur J Clin Microbiol Infect Dis 2014;33:1-6.

13. Levy ER, Swami S, Dubois SG, Wendt R, Banerjee R. Rates and appropriateness of antimicrobial prescribing at an academic children's hospital, 2007-2010. Infect Control Hosp Epidemiol 2012;33:346-53.

14. Gerber JS, Kronman MP, Ross RK, et al. Identifying targets for antimicrobial stewardship in children's hospitals. Infect Control Hosp Epidemiol 2013;34:1252-8.

15. Hersh AL, De Lurgio SA, Thurm C, et al. Antimicrobial stewardship programs in freestanding children's hospitals. Pediatrics 2015;135:33-9.

16. Hersh AL, Beekmann SE, Polgreen PM, Zaoutis TE, Newland JG. Antimicrobial stewardship programs in pediatrics. Infect Control Hops Epidemiol 2009;30:1211-17.

17. Dellit TH, Owens RC, McGowan JE Jr, et al. Infectious Diseases Society of America and the Society for Healthcare Epidemiology of America. Guidelines for developing an institutional program to enhance antimicrobial stewardship. Clin Infect Dis 2007;44:159-77.

18. Ganguly NK, Arora NK, Chandy SJ, et al. Rationalizing antibiotic use to limit antibiotic resistance in India. Indian J Med Res 2011;134:281-94.

19. Dalton BR, Sabuda DM, Bresee LC, Conly JM. Assessment of antimicrobial metrics; days of therapy versus defined daily doses and pharmacy dispensing records versus nursing administration data. Infect Control Hosp Epidemiol 2015;36:688-94. 


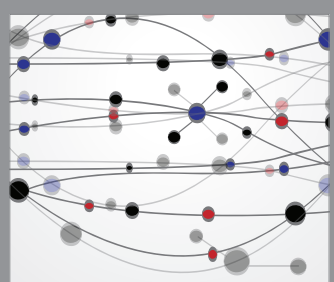

The Scientific World Journal
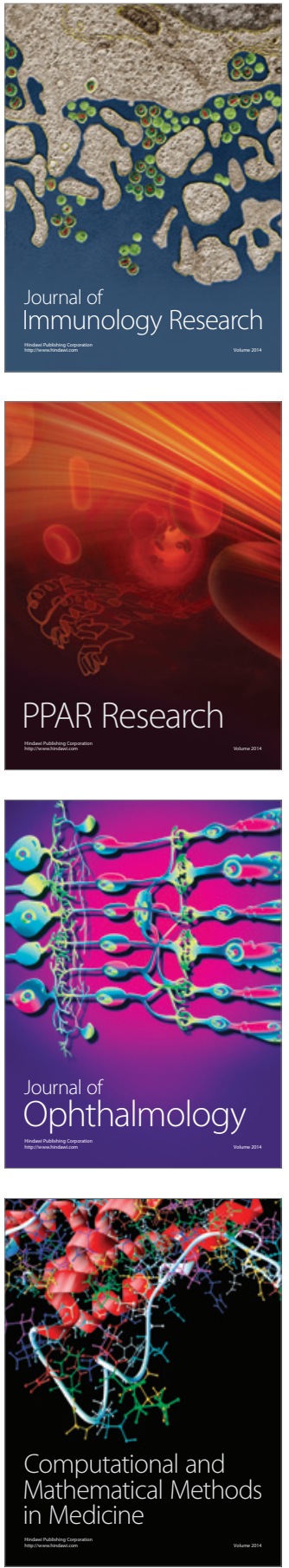

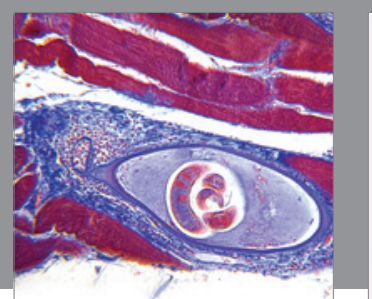

Gastroenterology Research and Practice

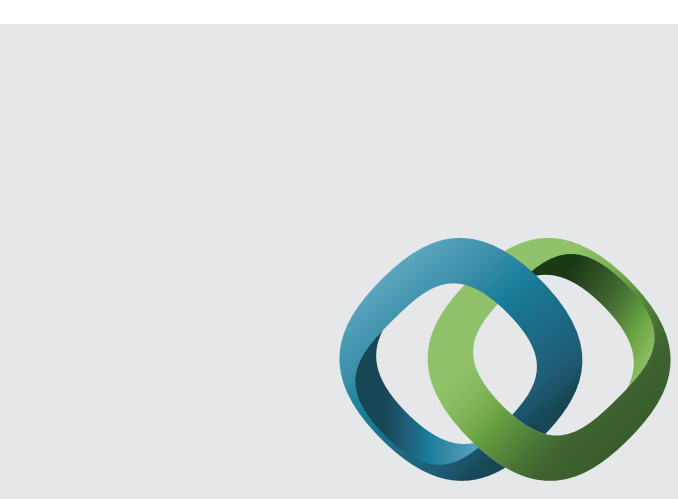

\section{Hindawi}

Submit your manuscripts at

http://www.hindawi.com
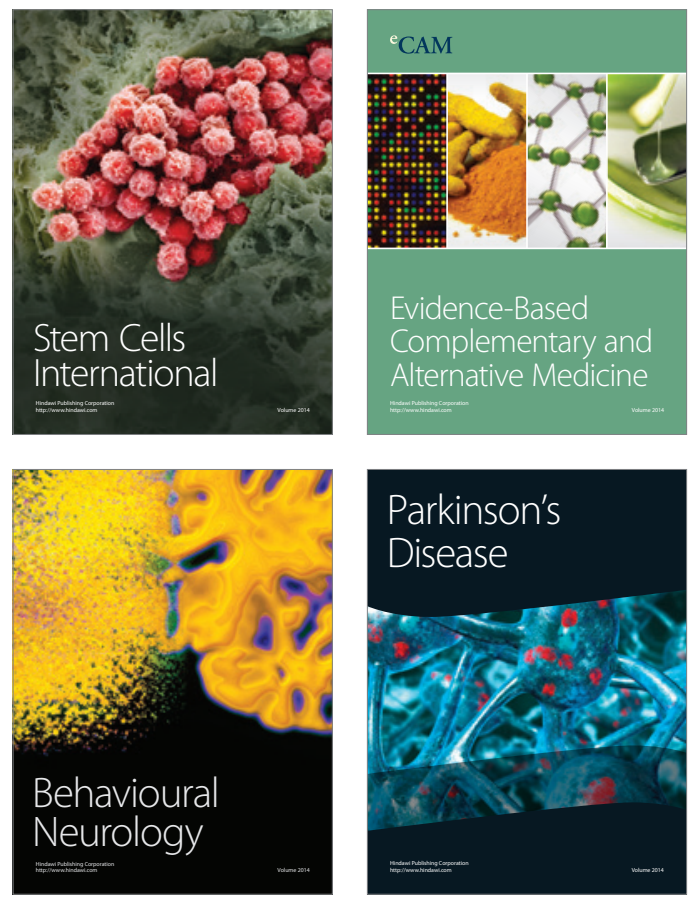
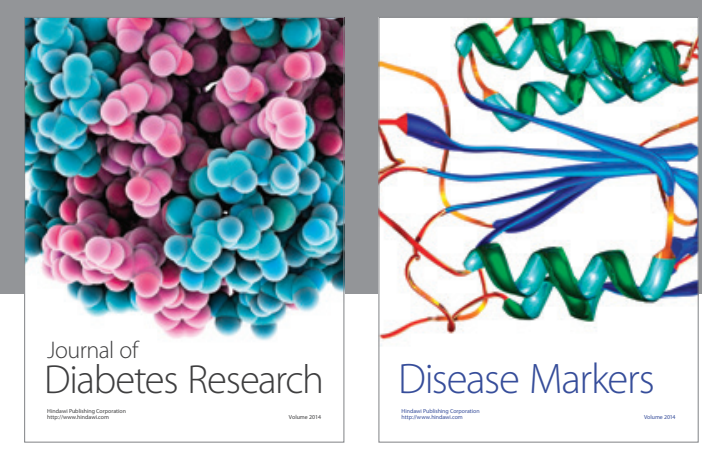

Disease Markers
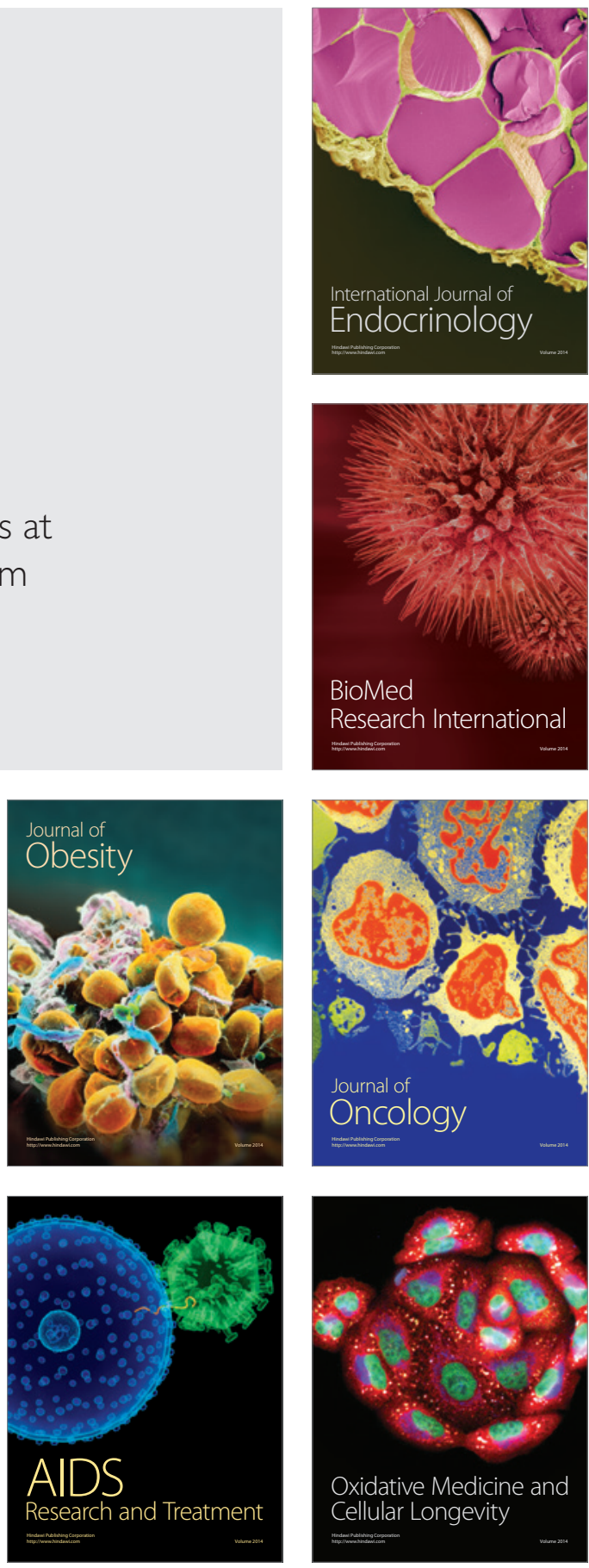